\title{
WHAT INFLUENCES CHILD DIETARY DIVERSITY? EMPIRICAL EVIDENCE FROM SINDA DISTRICT OF EASTERN ZAMBIA
}

\author{
Christopher Bupe Mulenga ${ }^{1 \bowtie}$ \\ ${ }^{1}$ Ministry of Agriculture, Petauke District, Zambia
}

\begin{abstract}
It is well documented in various studies carried out in Sub-Saharan Africa that dietary diversity is a major challenge for most households. This is true even in places that are known to produce a wide variety of food. Therefore, the purpose of this study was to determine the levels of child dietary diversity and to understand the factors that influence child dietary diversity. The study empirically established that child dietary diversity in Sinda district of Eastern Zambia was low, with a mean dietary diversity score of 3.6. The factors significantly influencing child dietary diversity were found to be the mothers' education, age of child, ownership of livestock and participation in nutrition trainings. It is recommended to invest in strategies that will promote maternal education, diversification of crops and livestock rearing and the scaling up of nutrition trainings based on a multi-sectoral approach.
\end{abstract}

Keywords: dietary diversity, child, food security, eastern Zambia

\section{INTRODUCTION}

Dietary diversity is defined as the range of foods or food groups constituting the diet of a given individual, household or community (Arimond and Ruel, 2004). Kennedy et al. (2009) argued that a diet which is sufficiently diverse may reflect nutrient adequacy. It is well documented that malnutrition is a major problem in Zambia, and poor dietary diversity was found to be a key predictor of child stunting (Mulenga et al., 2017).
The objective of this study was to determine the factors influencing child dietary diversity in the rural Zambian context, particularly in Sinda district of Zambia. The study also determined the level of child dietary diversity in Sinda district of Eastern Zambia, and contributed to the knowledge base required by various actors in combating the scourge of malnutrition.

\section{LITERATURE REVIEW}

A monotonous diet can be used as an indicator of poverty and poor nutrition (Golden and Golden, 1991). Bulky and monotonous diets are typical in communities and households with high rates of malnutrition. These diets predominantly comprise cereals, roots and tubers accounting for energy intake and, in some cases, smaller proportions of protein and micronutrient intakes as evidenced by (Hautvast et al., 1999; Onyango et al., 1998; Tarini et al., 1999). Several determinants of child dietary diversity have been identified in different studies carried out across the world. In their study carried out in Ethiopia, Dangura and Gebremedhin (2017) found that nutrition education and the implementation of a nutrition-sensitive agriculture can significantly enhance dietary diversity of children (aged 6-23 months). In a similar study, Woldehanna and Berhman (2013) found that family size, mothers' education level, price of staple and other food items, gender of household head and access to electricity have a significant effect on child dietary

\footnotetext{
$\bowtie$ MSc Christopher Bupe Mulenga, Ministry of Agriculture, P.O. Box 560001, Petauke district, Zambia, e-mail: cmulenga85@ yahoo.com; https://orcid.org/0000-0003-0726-188x
} 
diversity and the likelihood of consuming micronutrient rich foods. Taruvinga et al. (2013), in a study carried out in South Africa, found a positive influence of gender, education, income, access to home gardens and ownership of small livestock in attaining high dietary diversity. Kumar et al. (2015) established a strong positive association between production diversity and dietary diversity among younger children aged 6-23 months in central Zambia, and concluded that there is low agricultural diversity, low dietary diversity and high levels of chronic malnutrition overall in the area.

Living in a rural area increased the risk of low dietary diversity, presence of socioeconomic challenges and lack of nutrition knowledge (Mkemwa, 2015). It is suggested that supporting investments in diversified livelihood systems in general and in small livestock assets, such as poultry in particular, are viable intervention measures that improve household food security and nutrition for very poor, marginalized smallholders (Romeo et al., 2016).

\section{METHODOLOGY}

The cross-sectional study was conducted in Sinda district, a newly created rural district in eastern Zambia, during the period from January to May 2017.

A multi-stage sampling technique was used to collect primary data using a structured questionnaire from 253 respondents. In the first stage of sampling, two (2) agricultural blocks were identified in the district and were selected by simple random sampling technique to account for time, financial and other resource limitations. In the second stage, six (6) camps were selected by simple random sampling and, in a similar fashion, three (3) villages per camp, four (4) households per village and finally one (1) mother and child pair per household selected. The youngest child being within the age bracket of 6-60 months was the inclusion criterion.

In this study, a single 24-hour maternal report on food consumed was compared against the checklist of 7 food groups as proposed by Kennedy et al. (2011). The presence or absence of specific food groups consumed in the last 24 hours is determinant for an individual dietary diversity score (IDDS). The score is continuous, ranging from 0 to 7 , and is based on whether a child consumed any of the 7 food groups in the last 24 hours prior to the interview.

All the food items consumed by the participants were categorized into the following 7 food groups:
Group 1 - Cereal Grains, roots and tubers; Group 2 Legumes and nuts; Group 3 - Diary Products; Group 4 - Flesh foods; Group 5 - Eggs; Group 6 - Vitamin A fruits and vegetables; and Group 7 - other fruits and vegetables. This further allowed the researcher to come up with the following dietary diversity score bands: 0 to 3 food groups $=$ low dietary diversity score; 4 to 5 $=$ medium dietary diversity score; 6 to 7 food groups $=$ high dietary diversity score.

\section{Data analysis}

Once collected, the data was coded, entered into Excel and subsequently exported to SPSS version 20 for analysis. The analysis was performed to obtain descriptive statistics (percentages and frequencies). Also, a multiple linear regression analysis was carried out to determine the factors affecting child dietary diversity. Dietary diversity is usually measured by summing the number of foods or, more often, by counting the number of food groups consumed over a reference period (Ruel, 2003; Vakili et al., 2013). At household level, dietary diversity is often used as proxy for determining food access while at individual level as a reflection of dietary quality (Vakili et al., 2013). The reference period usually ranges from one day (24 hours) to three days, but a seven-day period is also often used (Kennedy et al., 2011). In this survey, individual dietary diversity was assessed for a 24-hour reference period.

\section{Model specification}

The multiple linear regression model specification was employed to examine the effects of demographic and socioeconomic factors (predictors) that influence child dietary diversity. The dependent variable (individual dietary diversity score) is continuous, hence the use of multiple linear regression. In this respect, the LS estimates are: linear, unbiased, with minimum variance, consistent and normally distributed (Gujarati, 2003). The multiple linear regression model may be expressed as (Gujarati, 2003):

$$
Y_{\mathrm{i}}=\beta_{0}+\beta_{\mathrm{i}} X_{\mathrm{i}}+\varepsilon_{\mathrm{i}}
$$

Where $Y_{\mathrm{i}}$ is the individual dietary diversity score, $\beta_{\mathrm{i}}$ are the parameters to be estimated, $\beta_{0}$ is a constant and $X_{\mathrm{i}}$ are the demographic and socioeconomic factors which influence individual dietary diversity. The model was specified explicitly as: 


$$
\begin{gathered}
Y=B_{0}+B_{1} X_{1}+B_{2} X_{2}+B_{3} X_{3}+B_{4} X_{4}+B_{5} X_{5}+B_{6} X_{6}+ \\
B_{7} X_{7}+B_{8} X_{8}+U
\end{gathered}
$$

Where:

$Y=$ Individual dietary diversity score

$X_{1}=$ child age, $X_{2}=$ annual income, $X_{3}=$ maternal education, $X_{4}=$ participated in nutrition training, $X_{5}=$ land under conservation agriculture, $X_{6}=$ ownership of livestock, $X_{7}=$ grow fruit and vegetables, $X_{8}=$ food insecurity, $U=$ error term

\section{RESULTS AND DISCUSSION}

Figure 1 gives a picture of the dietary diversity situation in Sinda district. It was established that the average dietary diversity score was 3.6 food groups. This was found to be consistent with findings by Hailemariam et al. (2018) who highlight the fact that most households consume diets that are below the accepted minimum of 4 food groups necessary to reap rewards of good nutrition.

The socio-economic characteristics of interest are presented in Table 1 and highlight that food insecure households account for $34.8 \%$. Households that had child caregivers participate in nutrition trainings had a share of $48.6 \%$ while maternal education was found to be at $68 \%$. The study found that $55.7 \%$ of households

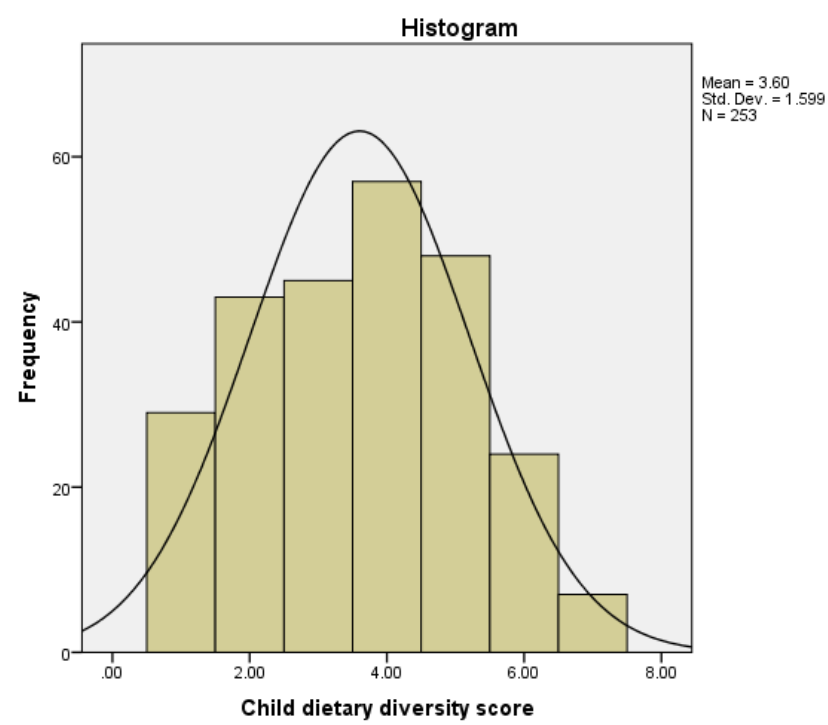

Fig. 1. Histogram for the mean dietary diversity score Source: field study (2017).
Table 1. Socioeconomic characteristics

\begin{tabular}{lrc}
\hline \multicolumn{1}{c}{ Variable } & Frequency & $\begin{array}{c}\text { Percent } \\
(\%)\end{array}$ \\
\hline Food insecurity & 88 & 34.8 \\
Participated in nutrition trainings & 123 & 48.6 \\
Households owning livestock & 141 & 55.7 \\
Households growing vegetables and fruits & 66 & 26.1 \\
Maternal education & 172 & 68 \\
\hline
\end{tabular}

$\mathrm{N}=253$

Source: field study (2017).

owned livestock and only $26.1 \%$ of households produced vegetables and fruits.

When it comes to annual household income, the highest number of households fell in the income bracket ranging from ZMW 501 to ZMW 3000, accounting for $33.6 \%$ of households, as shown in Table 2 .

Table 2. Annual household income

\begin{tabular}{lcc}
\hline Annual income (ZMW) & Frequency & Percentage \\
\hline 0 to 500 & 70 & 27.7 \\
501 to 3000 & 85 & 33.6 \\
3001 to 10000 & 83 & 32.8 \\
10001 to 50000 & 15 & 5.9 \\
\hline
\end{tabular}

$\mathrm{N}=253$; at the time of the research, 1 USD was equivalent to 10 Zambian Kwacha (ZMW).

Source: field study (2017).

Table 2 highlights the fact that most households earn less than 1 USD per day, the challenge being that this income source is usually active once a year as it depends on rain-fed agricultural practices. This is consistent with results by the CSO (2011).

The findings in Table 3 reveal that $46.2 \%$ of the children consumed less than three food groups, $41.5 \%$ of the children surveyed followed a diet deemed to be at a medium diversity level, and only $12.3 \%$ of the children surveyed consumed 6 to 7 food groups, which is deemed to be a high dietary diversity. This is consistent with findings as discussed by Disha et al. (2012). 
Mulenga, C. B. (2018). What influences child dietary diversity? Empirical evidence from Sinda District of Eastern Zambia. J. Agribus. Rural Dev., 4(50), 429-434. http://dx.doi.org/10.17306/J.JARD.2018.00430

Table 3. Child dietary diversity by number of children

\begin{tabular}{lcc}
\hline & Frequency & Percent (\%) \\
\hline Low IDDS & 117 & 46.2 \\
Medium IDDS & 105 & 41.5 \\
High IDDS & 31 & 12.3 \\
Total & 253 & 100.0 \\
\hline
\end{tabular}

$\mathrm{N}=253$

Source: field study (2017).

Table 4. Frequency distribution of children's consumption of 7 major food groups

\begin{tabular}{lcc}
\hline \multicolumn{1}{c}{ Food item } & Frequency & $\begin{array}{c}\text { Percent- } \\
\text { age (\%) }\end{array}$ \\
\hline Cereal, porridge, bread, rice, noodles & 241 & 95.2 \\
$\begin{array}{l}\text { Beans, peas, lentils, soya, groundnuts } \\
\text { Lactogen, milk, yoghurt, soured milk, } \\
\text { cheese }\end{array}$ & 64 & 64.8 \\
$\begin{array}{l}\text { Liver, kidney, heart, beef, goat, chicken, } \\
\text { duck, fish, pork, insects }\end{array}$ & 104 & 41.1 \\
$\begin{array}{l}\text { Eggs } \\
\text { Pumpkin, carrots, squash, sweet potatoes }\end{array}$ & 167 & 66 \\
$\begin{array}{l}\text { Dark green vegetables, oranges, man- } \\
\text { goes, pawpaws, masuku }\end{array}$ & 74 & 29.2 \\
\hline
\end{tabular}

$\mathrm{N}=253$.

Source: field study (2017).

The results in table 4 indicate that cereals were the most widely consumed food group, followed by orangefleshed vegetables and legumes. These findings are consistent with other studies by Romeo et al. (2016) which report a high consumption of starchy and legume-based diets while also revealing that more households are consuming vitamin A-rich crops, such as tubers and vegetable fruits.

The trend in Table 5 shows that dietary diversity increases with the increased level of mothers' education. The 136 children with medium-to-high dietary diversity had $15 \%$ of mothers with no formal education and $36 \%$ of mothers having attended grades $1-4$. As regards mothers attaining grades 5-12, the study showed that $48 \%$ had children exhibiting medium-to-high dietary
Table 5. Child dietary diversity by mothers' education

\begin{tabular}{lccrrr}
\hline & No education & G1-4 & G5-7 & G8-12 & Total \\
\hline Low IDDS & 60 & 42 & 8 & 7 & 117 \\
Medium IDDS & 15 & 42 & 31 & 17 & 105 \\
High IDDS & 6 & 7 & 9 & 9 & 31 \\
Total & 81 & 91 & 48 & 33 & 253 \\
\hline
\end{tabular}

$\mathrm{N}=253$.

Source: field study (2017).

Table 6. Individual dietary diversity by child age

\begin{tabular}{lcccc}
\hline & \multicolumn{3}{c}{ Child age (months) } & Total \\
\cline { 2 - 4 } & $6-23$ & $24-36$ & $37-59$ & \\
\hline Low IDDS & 70 & 22 & 25 & 117 \\
Medium IDDS & 49 & 27 & 29 & 105 \\
High IDDS & 18 & 7 & 6 & 31 \\
Total & 137 & 55 & 60 & 253 \\
\hline
\end{tabular}

$\mathrm{N}=253$.

Source: field study (2017).

diversity. This is consistent with findings by Taruvinga et al. (2013).

When synthesizing the child dietary diversity score by child age categories, the results show that of the 117 children who had low dietary diversity, 59.8\% were in the age bracket of 6-23 months, $18.8 \%$ were aged 24-36 months and $21.4 \%$ were aged $37-59$ months. This reflects a situation where children who are in the critical period of 6-23 months (are within the first 1000 days of their life and vulnerable to stunting) are being fed on a poor diet. This is consistent with findings by Kumar et al. (2015).

This cross tabulation in Table 7 indicates that $79 \%$ of the 117 children with low dietary diversity came from households who did not grow fruits or vegetables. Clearly, there is a favorable trend for the households that grew fruits or vegetables as discussed by Taruvinga et al. (2013) who recommended home gardens as a way to increase the levels of dietary diversity. Furthermore, investing in nutrition-sensitive agriculture interventions in conjunction with market integration could yield gains in reducing child undernutrition as discussed by Hirvonen and Hoddinott (2017). 
Table 7. Individual dietary diversity by households growing fruits and vegetables

\begin{tabular}{lccc}
\hline & \multicolumn{2}{c}{ Grow fruit and vegetables } & Total \\
\cline { 2 - 3 } & No & Yes & \\
\hline Low IDDS & 93 & 24 & 117 \\
Medium IDDS & 72 & 33 & 105 \\
High IDDS & 22 & 9 & 31 \\
Total & 187 & 66 & 253 \\
\hline
\end{tabular}

$\mathrm{N}=253$.

Source: field study (2017).

Table 8. Individual dietary diversity by households owning livestock

\begin{tabular}{lccc}
\hline & \multicolumn{2}{c}{ Own livestock } & Total \\
\cline { 2 - 3 } & no & yes & \\
\hline Low IDDS & 65 & 52 & 117 \\
Medium IDDS & 34 & 71 & 105 \\
High IDDS & 13 & 18 & 31 \\
Total & 112 & 141 & 253 \\
\hline
\end{tabular}

$\mathrm{N}=253$.

Source: field study (2017).
The results in Table 8 show that children coming from households owning livestock indicated an increased dietary diversity. As for the 136 children with a medium-to-high individual dietary score, $34 \%$ of these came from households that did not own livestock while $65 \%$ came from households that owned livestock. This trend is consistent with findings from studies by Romeo et al. (2016).

The results of multiple linear regression, as shown in Table 9, suggest that for each unit increase in mothers' education, there is a 0.186 unit increase in dietary diversity; and for each unit increase in child age, the results show a 0.012 unit increase in dietary diversity. For each unit increase in ownership of livestock, there is a 0.405 increase in dietary diversity. Also, the study unearthed that a unit increase in the caregivers' participation in nutrition trainings would result in a predicted 0.588 increase in dietary diversity. In summary, the results show that child dietary diversity was positively and significantly influenced by mothers' years of education, child age, household ownership of livestock and mothers' participation in nutrition training programs. An increase in any of these variables will lead to an increase in child dietary diversity. This is consistent with studies carried out by Dangura and Gebremedhin (2017).

Table 9. Summary results of the linear regression of the most influential factors determining child dietary diversity

\begin{tabular}{|c|c|c|c|c|c|}
\hline \multirow{2}{*}{ Model } & \multicolumn{2}{|c|}{ Unstandardized coefficients } & \multirow{2}{*}{$\begin{array}{c}\begin{array}{c}\text { Standardized } \\
\text { coefficients }\end{array} \\
\text { Beta }\end{array}$} & \multirow{2}{*}{$\mathrm{t}$} & \multirow{2}{*}{ Sig. } \\
\hline & $B$ & std. error & & & \\
\hline (Constant) & 2.152 & .224 & & 9.624 & .000 \\
\hline Annual income & $-2.562 \mathrm{E}-006$ & .000 & -.010 & -.161 & .872 \\
\hline Mothers' education & .186 & .028 & .379 & 6.657 & $.000 *$ \\
\hline Age of child & .012 & .005 & .126 & 2.260 & $.025^{*}$ \\
\hline Land under Conservation Agriculture & -.059 & .081 & -.044 & -.725 & .469 \\
\hline Own livestock & .405 & .198 & .125 & 2.043 & $.042 *$ \\
\hline Grow fruit and vegetables & .270 & .207 & .074 & 1.306 & .193 \\
\hline Food insecurity & -.022 & .186 & -.007 & -.117 & .907 \\
\hline Participated in nutrition training & .588 & .186 & .184 & 3.162 & $.002 *$ \\
\hline
\end{tabular}

$\mathrm{F}=10.978 ; \mathrm{R}=0.541 ; \mathrm{R}^{2}=0.265$.

* Significant at $0.05, \mathrm{~N}=253$.

Source: field study (2017). 


\section{CONCLUSION}

The study empirically established that child dietary diversity in Sinda district of Eastern Zambia was low. The factors significantly influencing child dietary diversity were found to be mothers' education, age of child, ownership of livestock and mothers' (caregivers') participation in nutrition trainings. It is recommended to invest in strategies that will promote maternal education, diversification of crops and livestock rearing and the scaling up of nutrition trainings based on a multi-sectoral approach to ensure no child is left behind in the improvement of dietary diversity.

\section{ACKNOWLEDGEMENT}

The author is grateful to the Management and staff of the Ministry of Agriculture, Sinda district, for their support at the survey stage of the research.

\section{REFERENCES}

Arimond, M., Ruel, M. T. (2004). Dietary diversity is associated with child nutritional status: evidence from 11 demographic and health surveys. J. Nutr., 134(10), 2579-2585.

CSO (Central Statistical Office). (2011). Living conditions monitoring survey report 2006 and 2010. Retrieved from: https://www.zamstats.gov.zm/phocadownload/Living Conditions/2006-2010\%20LCMS\%20Final\%20Report. pdf

Dangura, D., Gebremedhin, S. (2017). Dietary diversity and associated factors among children 6-23 months of age in Gorche district, Southern Ethiopia: Cross-sectional study. BMC pediatrics, 17(1), 6 .

Disha, A. D., Rawat, R., Subandoro, A., Menon, P. (2012). Infant and young child feeding (IYCF) practices in Ethiopia and Zambia and their association with child nutrition: analysis of demographic and health survey data. Afr. J. Food Agric. Nutr. Dev., 12(2), 5895-5914.

Golden, B. E., Golden, M. H. N. (1991). Relationships among dietary quality, children's appetites, growth stunting, and efficiency of growth in poor populations. Food Nutr. Bull., 13(2), 105-109.

Gujarati, D. N. (2003). Basic econometrics. New York: McGraw-Hill.

Hailemariam, T., Girmay, T., Girmay, G. (2018). Determinants of individual dietary diversity score of children less than five years old in the southern zone of Tigray, Ethiopia. Afr. J. Food Agric. Nutr. Dev., 18(1), 13034-13051.
Hautvast, J. L. A., Van der Heijden, L. J. M., Luneta, A. K., Van Staveren, W. A., Tolboom, J. J. M., Van Gastel, S. M. (1999). Food consumption of young stunted and nonstunted children in rural Zambia. Eur. J. Clin. Nutr., 53(1), $50-59$.

Hirvonen, K., Hoddinott, J. (2017). Agricultural production and children's diets: Evidence from rural Ethiopia. Agric. Econ., 48(4), 469-480.

Kennedy, G., Ballard, T., Dop, M. C. (2011). Guidelines for measuring household and individual dietary diversity. FAO.

Kennedy, G. L., Fanou-Fogny, N. M. L., Seghieri, C., Brouwer, I. D. (2009). Dietary diversity as a measure of the micronutrient adequacy of women's diets: results from Bamako, Mali site. Academy for Educational Development.

Mkemwa, T. H. (2015). Eating behaviors and dietary diversity among adults in Morogoro urban, Rural and Mvomero districts (Doctoral dissertation, Sokoine University of Agriculture).

Mulenga, C. B., Gubo, Q., Matsalabi, A. A. (2017). Examining the Factors Influencing Child Stunting Among Rural Households in Zambia: The Case of Sinda District. Dev. Countr. Stud., 7(8), 55-62. Retrieved from: www.iiste.org

Kumar, N., Harris, J., Rawat, R. (2015). If they grow it, will they eat and grow? Evidence from Zambia on agricultural diversity and child undernutrition. J. Dev. Stud., 51(8), 1060-1077.

Onyango, A., Koski, K. G., Tucker, K. L. (1998). Food diversity versus breastfeeding choice in determining anthropometric status in rural Kenyan toddlers. Int. J. Epidemiol., 27(3), 484-489.

Ruel, M. T. (2003). Is dietary diversity an indicator of food security or dietary quality? A review of measurement issues and research needs. Food Nutr. Bull., 24(2), 231-232.

Romeo, A., Meerman, J., Demeke, M., Scognamillo, A., Asfaw, S. (2016). Linking farm diversification to household diet diversification: evidence from a sample of Kenyan ultra-poor farmers. Food Sec., 8(6), 1069-1085.

Tarini, A., Bakari, S., Delisle, H. (1999). The overall nutritional quality of the diet is reflected in the growth of Nigerian children.Santé (Montrouge, France), 9(1), 23-31.

Taruvinga, A., Muchenje, V., Mushunje, A. (2013). Determinants of rural household dietary diversity: The case of Amatole and Nyandeni districts, South Africa. Int. J. Dev. Sustain., 2(4), 2233-2247.

Vakili, M., Abedi, P., Sharifi, M., Hosseini, M. (2013). Dietary diversity and its related factors among adolescents: a survey in Ahvaz-Iran. Glob. J. Health Sci., 5(2), 181-186.

Woldehanna, T., Behrman, J. R. (2013). What Determines Ethiopian Children's Dietary Diversity?'. Center for the study of African Economics (CSAE) held at St. Catherine's college Oxford, 17-19. 